\title{
Design and Implementation of Stand-Alone Solar Home System with Electrical Fencing
}

\author{
Prof. Vinaya K. Thombare \\ Department of Electrical Engineering \\ Ashokrao Mane Group of Institutions \\ vkt@amgoi.edu.in
}

Aniket Nandkumar Shingare Department of Electrical Engineering Ashokrao Mane Group of Institutions shingareaniket2216@gmail.com

\author{
Vrushabh Subhash Shirgave \\ Department of Electrical Engineering \\ Ashokrao Mane Group of Institutions \\ vrushabhshirgave09@gmail.com \\ Prajakta Prakash Zende \\ Department of Electrical Engineering \\ Ashokrao Mane Group of Institutions \\ prajaktazende511@gmail.com
}

\author{
Sushant Anil Vhanawade \\ Department of Electrical Engineering \\ Ashokrao Mane Group of Institutions \\ vhanawadesushant@gmail.com \\ Pranali Bajrang Gaikwad \\ Department of Electrical Engineering \\ Ashokrao Mane Group of Institutions \\ pranaligaikwad1908@gmail.com
}

\begin{abstract}
Utilization of off-grid solar PV system is one of the availability approaches that can provide electricity to these villages from the remote area or mini grid home load system design for future purposeng to design and application of off-grid solar PV system, valued experience was gotten for popularizing off-grid solar PV system in the remote area of home load . which played an important exemplary role for utilization of solar energy in future. For remote area home/house security is very important. House is one of the basic needs of human being. A system is to be proposed which will protect the home from animals / birds, as which enter the house. A Solar / electric fence is provided around the home to protect the house from animal /birds/unknown human, so that they should not enter the house. If anyone touches electric fencing then a text message is sent to the owner's mobile by the use of GSM. This research offers harmless and user-friendly home security for better security.
\end{abstract}

\section{STAND ALONE OR OFF-GRID SYSTEM}

The off-grid system term states the system not relating to the grid facility [2]. Mainly the system which isn't connected to the main electrical grid is term as off-grid PV system and also called stand-alone system or mini grid system. The grid can generate the power and run there appliances and standalone system are suitable for the electrification for small and mini work quantity and community. Stand alone electrification system is using in remote areas and special purpose operations.[1]

The on-grid system which have facing many problems, such as load shading and power issue which can be breaking our continuously working and daily working. This problem is only one solution is stand-alone system [8].

This system are develop solar working model but we have choose only off-grid system for remote areas, for this system required panel, charge controller (MPPT), battery, inverter and our load [3].

\section{SITE ASSESSMENT}

In the introduction of solar photovoltaic (PV) clusters for private, commercial, or agricultural operations; a crucial idea is to determine the merits of the site. Identifying the place and position of the panels is a crucial step in designing a PV system as the later components will be streamlined to this step. A few concepts and tips one must keep in mind while performing the site assessment are: [sol

A. Stand-alone PV system with load

1) Home load

2) Electrical fencing

1) Home load

The home load taken as our home Lightning system and our power consumption load such as LED bulb load, fluorescent tube Etc.

\section{2) Electrical Fencing}

An electrical fencing is a barrier that use electric shock to the animal and peoples from the home boundary. Most electrical fencing are used for agriculture security from animals, but we are used in remote location home in security system.

\section{B. Stand-alone system components}

\section{1) Shade Analysis}

Shading can be a problem for the solar panels as they decrease the maximum power that can be generated. Several factors contribute to this issue, the most common cause of shade on a solar panel are;

1) Shade from neighbouring trees and buildings in vicinity,

2) typical cloudy weather, and

3) shade from adjacent solar panels. 


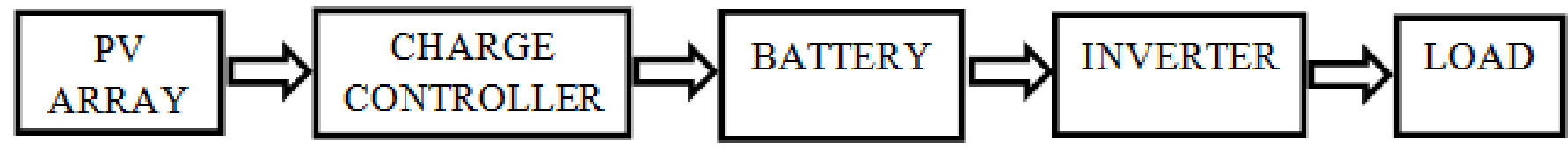

Fig. 1. Stand-alone solar system

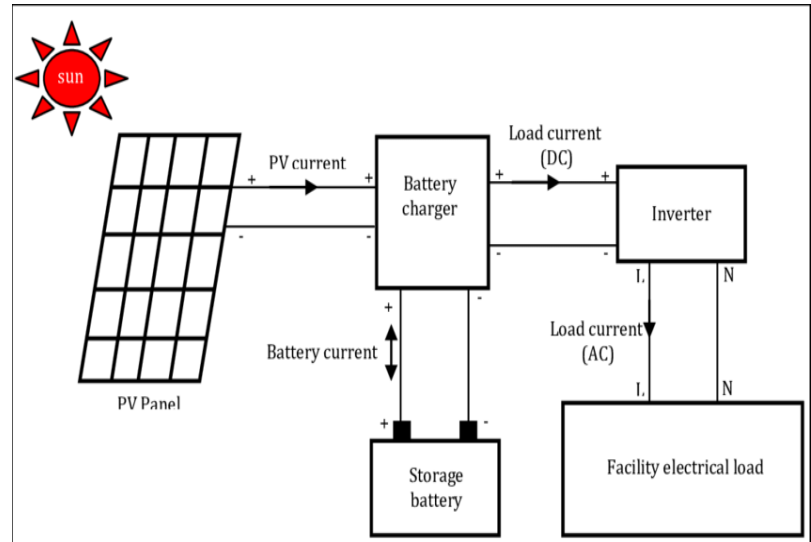

Fig. 2. Stand-alone PV system (off-grid)

While designing a solar PV system one must investigate these factors thoroughly so that maximum output can be obtained. One of the tools most commonly used is solar pathfinder which gives the direction of the sun throughout the year and how much any specific area will receive sunlight throughout the year. Apart from having this tool, it is important that the site assessment is done properly to locate the best site keeping in mind all the aspects.

\section{2) Sun hours}

Sun hours are important to know how much radiance will be required to generate the needed output wattage. This parameter gives us the knowledge of number of hours an area will receive maximum sunlight ( $5.5 \mathrm{hrs} /$ day).

\section{3) Tilt angle}

Tilt angle is the setting of the panels one needs to have to get the maximum radiance. Ideally the tilt angle is the latitude of the geographic location. It is suggested to have an adjustable panel frames as the sun hours keep changing with respect to the tilt in winters and summers. Hence for any area a specific tilt angle is calculated to get the maximum radiance throughout the year for a fixed panel. Also, it is advised to have the panels facing the south to get the maximum afternoon sun. An inclinometer is kept on the panel and the degrees are read to find the latitude of the area as it is perpendicular to the Sun's radiations when it is at its highest point in the sky. Compass measures the solar irradiance that will fall at a given tilt angle. It measures solar irradiance in Watts per meter Sq. $\left(\mathrm{W} / \mathrm{m}^{\wedge} 2\right)$

\section{Calculations of Area of solar panel}

Area required for panel $=$ Total load on panel $/ 150$ watt per $\mathrm{m}^{\wedge} 2$
Example:

\begin{tabular}{|l|l|l|l|l|l|l|}
\hline $\begin{array}{l}\text { Sr. } \\
\text { No }\end{array}$ & Appliances & $\begin{array}{l}\text { Pow } \\
\text { er } \\
\text { (W) }\end{array}$ & $\begin{array}{l}\text { No. of } \\
\text { appliance } \\
\text { s }\end{array}$ & $\begin{array}{l}\text { Daily } \\
\text { usag } \\
\text { e } \\
\text { hours }\end{array}$ & $\begin{array}{l}\text { Total } \\
\text { powe } \\
\text { r }\end{array}$ & $\begin{array}{l}\text { Total } \\
\text { energy }\end{array}$ \\
\cline { 3 - 7 } & (a) & (b) & (c) & $\left(\mathrm{a}^{*} \mathrm{~b}\right)$ & $\left(\mathrm{a}^{*} \mathrm{~b}^{*} \mathrm{c}\right)$ \\
\hline 1 & Tube light & 40 & 3 & 4 & 120 & 480 \\
\hline 2 & LED & 10 & 4 & 4 & 40 & 160 \\
\hline 3 & Fan & 55 & 3 & 3 & 165 & 495 \\
\hline 4 & $\begin{array}{l}\text { Electrical } \\
\text { fencing }\end{array}$ & 69 & 1 & 24 & 69 & 1656 \\
\hline & & & & Total & $\begin{array}{l}394 \\
\text { watt }\end{array}$ & $\begin{array}{l}2791 \mathrm{Wh} / \mathrm{da} \\
\mathrm{y}\end{array}$ \\
\hline
\end{tabular}

\section{4) Panel Sizing}

Once the total load to be energized using the PV system is calculated we must find out what area of solar panels would be required to generate that much amount of power. It is an inherent property of any panel to have internal losses. This factor should be kept in mind. As in the energy calculation we have already found the total watt-hours, for finding the wattage of panels that would be required we need to divide the total watt-hours with peak sun hours. Another useful tool that can be used is PV WATTS that helps use to calculate panel sizing just by putting the parameters such as energy consumption, tilt angle, and Sun hour.

[ losses in solar panel are 25\%]

- Losses of solar panel= Battery to Inverter Load * Losses of solar panel

- Power of solar panel= Total solar energy generated in panel / Hours of solar radiation

- $\quad$ No. of panel required= Power of solar panel / panel available in market

\begin{tabular}{|l|l|}
\hline Specification & Value \\
\hline Max. power & 250 watts \\
\hline Optimum operating voltage (Vmp) & 12 volts \\
\hline Optimum Operating Current (Imp) & 20.83 amp \\
\hline Open Circuit Voltage (Voc) & 18 volts \\
\hline Short Circuit Current (Isc) & 13.88 volts \\
\hline
\end{tabular}

\section{5) Battery Sizing:}

PV battery system assesses various strategies from a financial perspective. The valuable existence of the battery is limited to 5,000 cycles or in the planned living time of 20 years. The maintenance of photovoltaic and rechargeable annual activities and expenditure systems is set at $1.5 \%$ per the 
speculative cost. Assume that the cost system for the battery and $\mathrm{PV}$ is comparable to their size.

[ Battery available in market $=12 \mathrm{v} * 200 \mathrm{Ah}$ ]

- Calculation of energy storage $=$ Inverter input/battery losses

- No. of batteries = Energy storage of battery/Battery available in market

- Loss of batteries = battery to inverter load* Loss of batteries

\begin{tabular}{|l|l|}
\hline Lead acid battery & $50 \%$ (efficiency) \\
\hline Nominal voltage & $12 \mathrm{v}$ \\
\hline Current & 200 ah \\
\hline Power supply & 2400 watts \\
\hline
\end{tabular}

6) Inverter

Inverter deals with following main tasks of energy:

- Convert DC from PV module to AC

- Ensure that the cycle of alternating current cycles is 60 cycles

- Reduce voltage variations

- Ensure that the condition of the AC waveform is suitable for the application

Most system-connected inverters can be introduced externally, and most of the off-grid inverters are not weatherresistant. There are basically two types of grid intelligent Inverters: Those designed for batteries and those designed for systems without battery-connected inverter systems and give excellent void-quality strength. For matrix associations, the inverter should have a "useful-interactive" typeface, which is printed specifically for the publication name. 15 Gridconnected systems measure the power of extracting PV clusters rather than a bunch of prerequisite buildings. It asserts that what each power supply needs are what the matrix-related PV system can give naturally is drawn from the net. Invertors used for solar PV systems are usually based upon the total wattage of the solar panels, as the invertor will be continuously converting the power generated. The second consideration one must investigate, is the voltage level of the system. For example, if the system is designed to generate 2000 Watts at a voltage level of $12 \mathrm{~V}$ then the invertor selected should be rated $12 \mathrm{~V}, 2000$ Watts

- Load to Inverter loss= load*inverter loss (losses 20\%)

\begin{tabular}{|l|l|}
\hline Inverter rating & 4KVA \\
\hline Rated dc voltage & $220 \mathrm{~V}$ \\
\hline Phase & 1 single phase \\
\hline Nominal Voltage & $230 \mathrm{~V}$ \\
\hline Nominal Frequency & $50 \mathrm{HZ}$ \\
\hline Output Wave Form & Pure sine wave \\
\hline
\end{tabular}

\begin{tabular}{|l|l|}
\hline Cooling & Forced cool air \\
\hline Inverter efficiency & $92 \%$ \\
\hline Operating temperature & $0-40 \mathrm{o}$ C \\
\hline
\end{tabular}

\section{7) Charge Controller}

The charge controller, sometimes referred to as a photovoltaic controller or charger, is only necessary for the system which involves a battery. The main capacity of the charge controller is to counteract the battery spoofing. The basic function of charge controller is to monitor charging and discharging of the battery. It prevents the battery from being completely charged or discharged. This is important because over charging can lead to destruction of the battery and under charging decreases the battery life. Another important reason to use a charge controller is to prevent a reverse current flowing from battery to the system. There are two types of controllers that are widely available in the market;

1) Pulse width Modulation (PWM),

\section{2) Maximum Power Point Tracking (MPPT)}

Maximum Power Point Tracking (MPPT): This type of charger helps to get the optimum charging power for any given point of time and offers better efficiency that PWM. Though the MPPT charge controllers enable you to have better efficiencies and provides more power than compared to PWM for similar condition, the main cause of not opting for MPPT is price of it MPPT charge controllers are more expensive than PWM controllers. Keeping this parameter in mind, this project will be using a PWM charge controller for realizing the concept. To select the size of charge controller one must know the voltage level of the system and the maximum operating current. It is a usual practice to oversize the controller for safety reasons.

$$
\text { Vin }=12 \mathrm{v}, \mathrm{V} \text { out }=24 \mathrm{v}
$$

Boost converter: to improve voltage by base voltage to implement voltage

\section{ELECTRICAL FENCING:}

\section{A. Introduction}

The need of house is important as food is the basic need of humans. Development in the security of house is necessary in today's world. New technologies are invented day by day for various uses, methods and process are getting advanced, these new technology and advancement in process should be used or make in progress in the house secure. Development is needed in house security sector to protect from theft to their home caused due to many reasons. To prevent these losses to a system is to be designed.

Solar energy is abundant source of energy as it is free energy source, so it is necessary to make most use of solar energy. The system to be designed uses solar energy, a fencing is provided around the house, this fencing transfer signal, and so if any animal or human touches the fence may receive a 
short pulse it is just to threaten the animal / human. Thus, animals/human do not enter in the house.

\section{B. Hardware Specifications}

\section{1) Solar Panel}

Solar Panel is used to direct solar energy, solar panel used in this system is of $12 \mathrm{~V} / 300 \mathrm{~mA}$. The solar panel converts the solar energy to electric to transfer the electric pulse to fence. The use of solar energy is made as it reduce the cost of unnecessary electric supply and solar energy is an abundant resource.

\section{2) Battery}

Battery is used to store the charge, so that during night hours when there is no sun light the system should work smoothly. The battery is charged by the solar energy and when battery gets fully charge the battery is disconnected and the energy is stored in battery. In this system a battery of $12 \mathrm{~V}$ is used.

\section{3) Arduino UNO}

An Arduino is a microcontroller development board. Use of Arduino is to read values of sensors and control devices such as motors and lights. This board permits to upload programs to the board which can then interact with the devices in real world. This board helps to make things which can respond to the world. It helps to interact with real world things.

\section{a) Arduino uno with used equipment}

- $\quad \operatorname{AdAPTER}(5 \mathrm{v})$

\section{4) GSM Modem}

To alert user if any unusual attempts occur in the farm. When any attempts or problems occur. it will send text message to about the problem. GSM gives an ease to user for communication with devices, we have used sim 8001

\section{GSM 800L with Equipment Uses}

- Connector

- Antenna

In MATLAB Simulink R2016ac invereter Vout=18 volts , Iout $=14.88 \mathrm{amp}$

By adding [ 18 o 18] transformer(step-up) = v1/v2=i2/i1

Vout $=230 \mathrm{v}$, Iout $=1 \mathrm{amp}$

$$
=230 / \mathrm{v} 2=\mathrm{i} 2 / 14.88=
$$

\begin{tabular}{|l|l|l|}
\hline Name & Vout & Iout \\
\hline Invereter & $18 \mathrm{~V}$ & $14.88 \mathrm{Amp}$ \\
\hline $\begin{array}{l}\mathrm{1} 18 \quad 0 \quad 18] \\
\text { transformer(step-up) }\end{array}$ & $230 \mathrm{~V}$ & $1 \mathrm{Amp}$ \\
\hline
\end{tabular}

\section{SIMULATION RESULT}

A. For MATLAB results

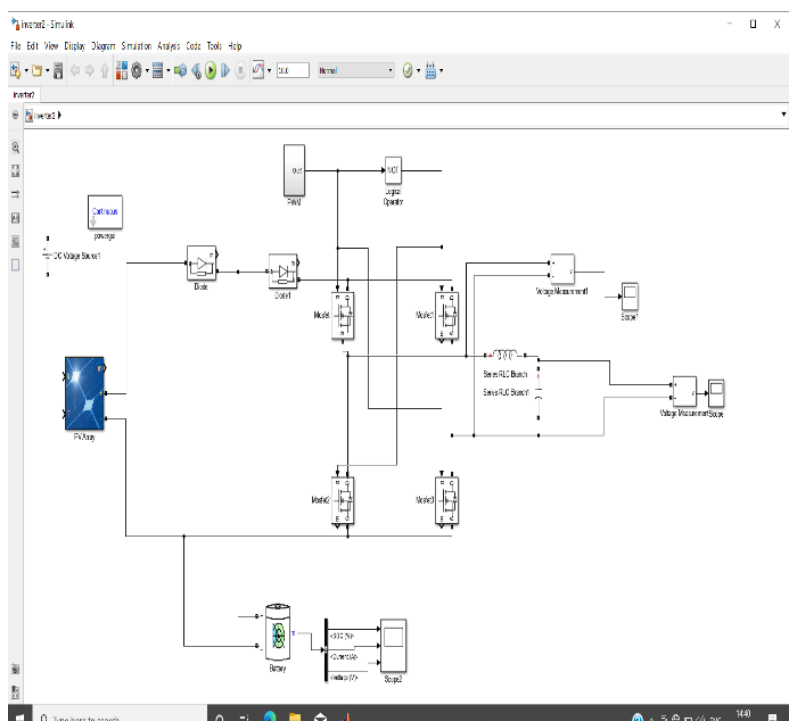

Fig. 3. MATLAB simulation results

\section{B. For proteus results}

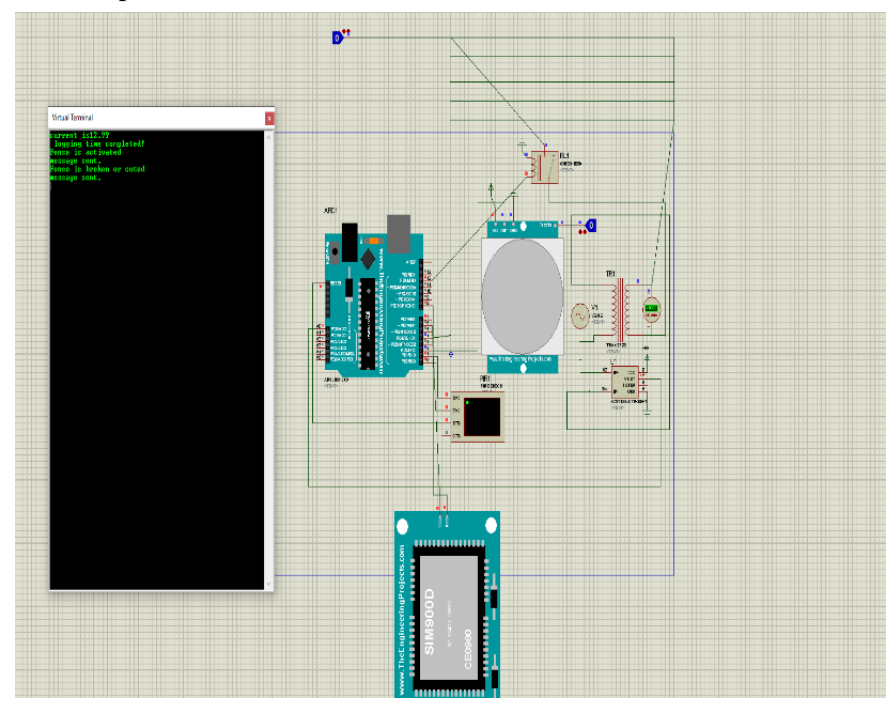

Fig. 4. Rresults of proteus simulation

\section{CONCLUSION}

It may be concluded that the use of a stand-alone PV system will be the best sustainable solution for our remote locative house for electricity supply. PV system are not operational continuously, unless if they are connected to a storage system. For rainy days it is going be a challenge for the PV modules to provide the required power, therefore a battery system is required to provide backup power to the housing load. 


\section{FUTURE SCOPE}

In future a solar tracking stand-alone system may be considered in order to get maximum energy from the sun. And an option for connecting to the grid may be considered should there be access to the electricity provider.

\section{ACKNOWLEDGMENT}

The authors would like to acknowledge the DBATU, Lonere University of Technology, Ashokrao Mane group of institutions, Vathar tarf Vadgaon, Department of Electrical Engineering, Maharashtra, India for all the facilities provided for writing this research paper.

\section{REFERENCES}

[1] Nunu Henroitta Mazibane and Prof SP Chowdhury Andre Tati Puati Zau and Mokopu Jayluke Malatji Department of Electrical Engineering Department of Electrical Engineering Tshwane University of Technology Tshwane University of Technology Pretoria, Gauteng, 0001, RSA Pretoria, Gauteng, 0001, RSA nhmazibane@gmail.com, spchowdhury2010@gmail.com_andretati800@gmail.com jaymokopu@gmail.com by "Design of an off-grid PV system for Mapetja rural village"

[2] Dr.Chetan singh Solanki by "SWARAJ BHARAT"

[3] Mingzhi Zhao, Zhizhang Liu School of Energy and Power Engineering Inner Mongolia University of Technology Hohhot, China zhaomingzhi2020@163.com by "Design and Application of Offgrid Solar PV System in Inner Mongolia of China"

[4] Brigitte Hauke, Application report SLVA4477B ,Dec 2011 ,revised Aug 2015 by Dr.K. by "Basic calculation of boost converter's power stage"

[5] Adithya Rajeev Electrical and Electronics Department Dayananda Sagar College of Engineering Bangalore, India pmadithyarajeev@gmail.com by "Design of an Off-Grid PV System for the Rural Community"

[6] Ned Mohan by "Power electronics" (second edition solution)

[7] Saad Amir by "Inverter design of Matlab Simulink"

[8] author Ayaz .A. Khmisani. By "Design methodology of off - grid PV solar power system"

[9] High power electric fencing by stand-alone PV generators for remote areas.

[10] Mayuri Chawala, Dr. Narendra Bawane. "The automatic solar based electric fencing by GSM (900D) and ARDUINO (UNO)"

[11] S. Y. Wong School of Engineering, Computing and Science Swinburne University of Technology (Sarawak) Kuching, Malaysia sywong@swinburne.edu.my A. Chai School of Engineering, Computing and Science Swinburne University of Technology (Sarawak) Kuching, Malaysia achai@ swinburne.edu. "An Off-grid Solar System for Rural Village in Malaysia"

[12] M.V. Santhi Lakshmi*, Dr. Ch. Sai babu**, GRKD Satya Prasad*** *JNTUK, PG Student, India. **Professor, JNTUK, India. ***HOD,
Dept. of EEE, Regency Institute of Technology, India. Email: santi.mynampati@gmail.com, grkdsp@yahoo.co.in__Design of off-grid homes with Renewable energy sources"

[13] M. Mahmudul Hasan Sajeeb*, Md. Aminur Rahman, Shaila Arif Department of Electrical and Electronic Engineering, Ahsanullah University of Science and Technology 141 -142 Love Road, Tejgaon I/A, Dhaka - 1215, Bangladesh. *mahmud.sajeeb08@gmail.com; aminur.rahman.eee@gmail.com; shaila221228@hotmail.com by "Feasibility Analysis of Solar DC Nano Grid for Off Grid Rural Bangladesh"

[14] R. Ramaprabha, Member, IEEE and B.L. Mathur by "Modelling and Simulation of Solar PV Array under Partial Shaded Conditions "

[15] Oladimeji Ibrahim, Member IEEE Nor Zaihar Yahaya, Member IEEE, Department of Electrical and Electronics Engineering Nordin Saad, Member IEEE Universiti Teknologi PETRONAS, Muhammad Wasif Umar Bander Seri Iskander, Perak 32610, Malaysia Universiti Teknologi PETRONAS reacholaibrahim@gmail.com Bandar Seri Iskandar, Perak 32610, Malaysia norzaihar_yahaya@petronas.com.my nordiss@petronas.com.my cmwasif@yahoo.com by "Matlab/Simulink Model of Solar PV Array with Perturb and Observe MPPT for Maximising PV Array Efficiency"

[16] Majid Ali Member IEEE1, Engr. Adnan Yousaf2, Engr. Furqan Ghafoor Seharan3 Department of Electrical Engineering, School of Engineering \& Technology, ICBS, Lahore Pakistan1 Department of Electrical Engineering, Faculty of Engineering \& Technology, Superior University, Lahore Pakistan2 Department of Electrical Engineering, School of Engineering \& Technology, ICBS, Lahore Pakistan3 engr.majidali.baig@gmail.com1 by "Feasibility Evaluation of Stand-alone Photovoltaic Systems for Residential Loads Engr."

[17] S. S. S. Ranjit1, C. F. Tan2 and S. K. Subramaniam1 1 Faculty of Electronics and Computer Engineering, 2 Faculty of Mechanical Engineering, Universiti Teknikal Malaysia Melaka, Hang Tuah Jaya, 76100 Durian Tunggal, Melaka, Malaysia. ranjit.singh@utem.edu.my_by "Implementation Off-Grid Solar Powered Technology to Electrify Existing Bus Stop"

[18] 1 Anusha Ramachandran, 2 Sairam Mannar, 3 Ashok Jhunjhunwala Electrical Engineering Department, Indian Institute of Technology Madras, Chennai India, 1 anusha@tenet.res.in; 2 sairam@tcoe.iitm.ac.in; 3 ashok@tenet.res.in by "Inverter less SolarDC System Design for Off Grid and Near Off-Grid Indian Homes"

[19] Sravankumar Jogunuri1, Ravish Kumar2, Deepak Kumar3 College of Agricultural Engineering \& Technology Anand Agricultural University, Godhra, India by "Sizing an Off-Grid Photovoltaic System (A Case Study)"

[20] Onur Ozdal MENGI Department of Energy Systems Engineering, Engineering Faculty, Giresun University, 28100 Giresun, Turkey e mail: onur.ozdal.mengi@giresun.edu.tr Ismail Hakk1 ALTAS Department of Electrical and Electronics Engineering, Engineering Faculty Karadeniz Technical University, 61080 Trabzon, Turkey e mail: ihaltas@ktu.edu.tr by “An Off-Grid PV/SC Green Energy Production System" 